\title{
Projeto Horta para o desenvolvimento da Educação Ambiental na Educação Infantil
}

\author{
Vegetable garden Project for the development of Environmental Education in Early \\ Childhood Education \\ Proyecto Horta para el desarrollo de la Educación Ambiental en la Educación Infantil \\ Larissa Costa Marvila ${ }^{1 *}$, Désirée Gonçalves Raggi².
}

\begin{abstract}
RESUMO
Objetivo: Revisar na literatura científica sobre projetos pedagógicos na conscientização da educação ambiental através de implantação de uma horta escolar, conceitos metodológicos, bem como, seu impacto na construção da consciência ambiental na sociedade. Métodos: Trata-se de uma pesquisa de abordagem qualitativa do tipo de revisão de literatura buscando responder a seguinte problemática $A$ horta como recurso didático: práticas pedagógicas para o desenvolvimento da consciência ambiental na Educação Infantil" podem contribuir para o desenvolvimento de hábitos e comportamentos relacionados com a formação da consciência ambiental? Resultados e Discussão: com resultado a esse modo, houve a intenção de desenvolver a consciência ambiental na formação dos educandos e de sensibilizar as crianças a buscarem valores que conduzam à preservação e ao cuidado com o meio ambiente através do projeto horta escolar, para alcançar os objetivos propostos, o estudo baseou-se nos princípios da Educação Ambiental expressos no artigo $4^{\circ}$ da Lei 9.794 de abril 1999. Considerações finais: Pode-se concluir que a aprendizagem das crianças pelo o projeto horta escolar, proporciona mudanças comportamentais e formação de hábitos saudáveis. As atividades pedagógicas e suas práticas no cultivo de hortaliças e a utilização na merenda escolar contribuíram para desenvolver a consciência ambiental nas crianças que levaram os conhecimento adquiridos no projeto para o seu convívio social.
\end{abstract}

Palavras-chave: Projeto, Horta Escolar, Educação Ambiental.

\begin{abstract}
Objective: To review in the scientific literature about pedagogical projects in environmental education awareness through the implementation of a school garden, methodological concepts, as well as its impact on the construction of environmental awareness in society. Methods: It is a research of qualitative approach of the type of literature review seeking to answer the following problematic The garden as a didactic resource: pedagogical practices for the development of environmental awareness in Early Childhood Education "may contribute to the development of habits and related behaviors with the formation of environmental awareness? Results and Discussion: In this way, there was an intention to develop environmental awareness in the education of the students and to make children aware of values that lead to preservation and care for the environment through the school garden project, in order to reach the objectives, the study was based on the principles of Environmental Education expressed in article 4 of Law 9,794 of April 1999. Final considerations: It can be concluded that the learning of children through the school garden project, provides behavioral changes and habit formation healthy. The pedagogical activities and their practices in the cultivation of
\end{abstract}

${ }^{1}$ Faculdade Vale do Cricaré. São Mateus - ES. *E- mail: larissa.costa.marvila@gmail.com

${ }^{2}$ Universidad del Norte - Revalidado pela Universidade Federal de Pernambuco - UFPE (2010).

SUBMETIDO EM: 3/2019

ACEITO EM: 4/2019

PUBLICADO EM: 7/2019

REAS/EJCH | Vol. Sup. 25 | e634 | DOI: https://doi.org/10.25248/reas.e634.2019 Página 1 de $\mathbf{5}$ 
vegetables and the use in the school lunch contributed to develop the environmental awareness in the children who took the knowledge acquired in the project to their social life.

Keywords: Project, School Vegetable Garden, Environmental Education.

\section{RESUMEN}

Objetivo: Revisar en la literatura científica sobre proyectos pedagógicos en la concientización de la educación ambiental a través de la implantación de una huerta escolar, conceptos metodológicos, así como su impacto en la construcción de la conciencia ambiental en la sociedad. Métodos: Se trata de una investigación de abordaje cualitativo del tipo de revisión de literatura buscando responder a la siguiente problemática La huerta como recurso didáctico: prácticas pedagógicas para el desarrollo de la conciencia ambiental en la Educación Infantil "pueden contribuir al desarrollo de hábitos y comportamientos relacionados con la formación de la conciencia ambiental? Resultados y Discusión: con resultado a ese modo, hubo la intención de desarrollar la conciencia ambiental en la formación de los educandos y de sensibilizar a los niños a buscar valores que conduzcan a la preservación y el cuidado con el medio ambiente a través del proyecto huerta escolar, para alcanzar los objetivos los objetivos propuestos, el estudio se basó en los principios de la Educación Ambiental expresados en el artículo 4 de la Ley 9.794 de abril de 1999. Consideraciones finales: Se puede concluir que el aprendizaje de los niños por el proyecto huerta escolar, proporciona cambios conductuales y formación de hábitos saludable. Las actividades pedagógicas y sus prácticas en el cultivo de hortalizas y la utilización en la merienda escolar contribuyeron a desarrollar la conciencia ambiental en los niños que llevaron los conocimientos adquiridos en el proyecto para su convivencia social.

Palabras clave: Proyecto, Horta Escolar, Educación Ambiental.

\section{INTRODUÇÃO}

A Educação Ambiental (EA) surge como um processo educativo, cujos saberes ultrapassam os conteúdos técnicos e científicos e se pautam na formação do ser humano completo. Assim o projeto horta escolar, está engajada no desenvolvimento de valores éticos e de regras políticas, que compreendem as relações sociais e econômicas, que incidem sobre questões acerca da distribuição entre os benefícios e prejuízos da apropriação e do uso dos recursos naturais (CRIBB SL 2010).

Portanto, deve estar voltada para a cidadania ativa considerando seu sentido de pertencimento e responsabilidade que, por meio da ação organizada e coletiva, busca compreender e superar as causas das estruturas e dos conjuntos de problemas ambientais (SORRENTINO M, et al 2005). Dessa maneira, é imprescindível que a EA seja inserida no espaço de ensino, pois a escola tem como função conscientizar acerca dos efeitos das ações humanas sobre a natureza.

Para o desenvolvimento do estudo a questão - problema será: Como o projeto "A horta como recurso didático: práticas pedagógicas para o desenvolvimento da consciência ambiental na Educação Infantil" podem contribuir para o desenvolvimento de hábitos e comportamentos relacionados com a formação da consciência ambiental? Relacionando tal realidade ao problema em questão, acredita-se que cabe à escola iniciar um processo de formação básica dos alunos no geral, e também aos profissionais, como docentes e diretamente envolvidos, fomentar discussões junto às crianças quanto à problemática do meio ambiente em que vivem (BECK U, 1999).

Para que haja soluções dos problemas ambientais é preciso de uma mudança radical no processo de conhecimento, valores, comportamentos realizados pela sociedade (JACOB IP, 2003).

O ambiente da horta escolar permite grande interação entre as pessoas envolvidas, contribui e proporciona o desenvolvimento da autonomia do aluno e a construção de conhecimentos em várias áreas do saber, por meio de práticas, se transformando em informações significativas para a compreensão de saber resolver de

REAS/EJCH | Vol. Sup. 25 | e634 | DOI: https://doi.org/10.25248/reas.e634.2019 Página 2 de $\mathbf{5}$ 
uma situação problema do seu cotidiano. Para aprofundamento deste tema, este estudo está fundamentado nas ideias de pensadores como Dewey J (1967), Freire P (2001).

Para tal será realizado um estudo bibliográfico, de modo a auxiliar na contribuição para o desenvolvimento da consciência ambiental, objeto deste estudo. E então, constatar através do projeto horta escolar das finalidades de trabalhar Educação Ambiental prescrita em Lei 9.794/1999 Brasil (1999).

O objetivo desta pesquisa é que professores utiliza a horta como recurso didático em suas aulas na educação infantil, e aos alunos a conseguirem conhecimentos através de suas práticas diárias, consequência de seus cuidados com a horta, desenvolvendo a consciência ambiental das crianças, cultivado esses aprendizado desde pequenos para que cheguem na vida adulta possa ser cidadãos mais sustentáveis.

\section{MÉTODOS}

Trata-se de pesquisa de abordagem qualitativa, trata-se de uma revisão da literatura, a metodologia utilizada seguiu os princípios da pesquisa bibliográfica visando ajuntar e verificar estudos científicos. Determinou-se principalmente a pesquisa em meios eletrônicos, gratuitos e de acesso público para pesquisa de fontes secundárias tais como livros didáticos, manuais e guias com a temática em questão.

A busca de materiais e o acesso ocorreu entre julho a dezembro de 2018. Os relatores utilizados foram: a horta escolar como recurso didático na educação infantil para o desenvolvimento da consciência ambiental, a proposta para os professores utilizarem uma horta na educação infantil como recurso didático.

Os métodos de estudos e as contribuições dos autores pesquisado favoreceu a descrição dos de projetos de trabalhar a horta como recurso didático na educação infantil, que impulsionam estes profissionais a buscarem novas estratégias de ensino da Educação Ambiental com a horta escolar.

\section{RESULTADOS E DISCUSSÕES}

Segundo Fetter SI et. al (2006) a horta escolar se torna um recurso importante na construção de conhecimento em variadas áreas como educação Ambiental, educação alimentar, Ciências Naturais, como as suas práticas na horta o contato com a terra, valorizando agricultura.

Rodrigues IOF, Freixo AA (2009) refere a horta como onde se cultiva plantas, mas quando as práticas de plantar hortaliças e os cuidados se juntam atividades didáticas e pedagógicas, se torna um lugar no qual acontece muita aprendizagem que se refere a rotina diária do aluno.

Para Gadotti M (2002) o educador deve estabelecer relações com os alunos, mudando o paradigma de ser o único transmissor de conhecimento, mas se tornado um facilitador para os alunos a encontrar a resposta de suas dúvidas e saber gerir e organizar o seu saber, orientar sobre valores fundamentais que levaram por toda sua vida.

\section{Implantação da horta em um ambiente escolar}

Para Currie KL. et. al. (2012) para implantar a horta é necessário a escolha do terreno a qual vai se transformar em uma horta, através de diálogo com os alunos, como também o tamanho do canteiro e quais sementes serem plantadas, explicar a responsabilidade dos alunos no cuidado e na manutenção com a horta.

De acordo Pimenta JC, Rodrigues KSM (2011), para iniciar a implantação da horta deve-se fazer um a limpeza no terreno para retira de entulhos erva daninhas etc. depois fazer as correções necessárias com o solo preparando os canteiros com matérias orgânicas na quantidade certa com esterco ou compostagem, após misturar e molhar bem para melhorar a qualidade das hortaliças.

Pimenta JC, Rodrigues KSM (2011) ressalta antes de plantar, o professor mostra aos alunos as sementes e as mudas que serão plantadas no canteiro, para que façam assimilação das plantas que irão colher e consumir em momentos posteriores. 
Capeletto JA (2009), os alunos poderão trazer sementes para ser plantada na horta escolar, como aquelas de envelope que são encontradas facilmente em lojas especializadas em agronomia ou em supermercado, que contam informações de cultivo época apropriada para planta de como cuidar das mudas.

Bezerra IA, Costa MF. (1992) discorre sobre a importante que os alunos façam parte de todo o ciclo da planta, possibilita a compreensão de toda etapa existente, a função da semente de germinar e se transformar em uma planta, a qual cresce e produz flores e por fim novas sementes.

Após o plantio da horta, necessitará de uma atenção especial em termo de irrigar, fazer a limpeza dos canteiros e os educandos poderá revezar neste trabalho Currie KL. et. al. (2012). Para Capeletto JA (1999) outros cuidados são necessários como a limpeza com a retirada de ervas daninhas o controle de inseto, transplantar mudas no canteiro, plantar semente para o replantio etc.

$\mathrm{Na}$ horta escolar o professor organizará os educandos para que faça a colheita no período certo, após envolver todo a turma no trabalho diário com cuidados, chegou o momento mais esperado a colheita (CAPELETTO JA, 1999).

A construção de uma horta escolar estimula os alunos adquirirem hábitos saudáveis, ao cuidar e vê o crescimento das hortaliças eles quem provar o fruto de seu trabalho e com isso aceitação desses alimentos é maior, apesar de serem mais saudáveis e nutritivos muitas crianças e adolescente os rejeita.

\section{A importância da horta no desenvolvimento da Educação Ambiental}

Para Fernandes MC. (2005) a horta se torna um recurso eficiente em atingir as metas almejadas, com este recurso pode ser trabalhada de forma interdisciplinar em diversas atividades.

Como afirma Cascino F. 2000, para que haja EA no ambiente escolar tem que ter atividades práticas de forma interdisciplinar para que possam ao enfrentar os problemas do cotidiano a resolvê-lo de maneira diferenciada. Essa prática de estar presente na formação do professor que sua aula seja na sala, mas também no ambiente extraclasse, que envolva toda comunidade escolar.

Segundo Morgado FS. (2006) ao inserir uma horta no ambiente escolar ela pode se transformar em um laboratório vivo a céu aberto, possibilita o professor trabalhar variadas atividades pedagógicas, desenvolvendo a consciência ambiental, hábitos saudáveis e o trabalho coletivo proporcionando a socialização.

Cribb SL. (2010) enfatiza que ao implantar uma horta na escola as atividades desenvolvidas nela ajuda os educandos a compreender a necessidade de preservar o meio ambiente, proporciona a cooperação através do trabalho coletivo com atividades práticas na horta e possibilitando os alunos ter contato com a natureza. As atividades realizadas na horta promovem o desenvolvimento da consciência ambiental. A Educação ambiental nos últimos os anos tenha assumido um papel muito importante de desenvolver a sociedade mais sustentável com os recursos natural do planeta também valores sociais e éticos (CARVALHO, ICM, 2006).

\section{CONSIDERAÇÕES FINAIS}

Conclui-se que a utizaçãa utilização da horta escolar para o desenvolvimento da consciência ambiental, através do mecanismo do recurso didadico com atividades prática diária no processo de aprendizagem, desenvolvendo os valor e a responsabilidades com o meio ambiente, o projeto horta escolar evidencia, claramente, que no trabalho pautado com a horta como um recurso didatico insere novas práticas e atitudes para uma uma construção de saberes que levaram para o meio social sobre a preservação do meio ambiente. Isso se dá também pela cooperação, percebida por meio do trabalho em equipe, que auxiliou no desenvolvimento dessas práticas sociais entre crianças da Educação Infantil, desenvolvendo as relações ecológicas a partir de valores sociais. Como esse projeto trabalha a sustentabilidade integrada com a horta, a manutenção e implantação da mesma contribui bastante no processo de aprendizagem, uma vez que proporciona aos alunos da Educação Infantil compreender a relação com o espaço natural que os cerca, estimulando hábitos saudáveis, atitudes que beneficiam a sociedade e a noção de preservação do meio em que vivem. 


\section{REFERÊNCIAS}

1. AYRES JRCM. Uma concepção hermenêutica de saúde. Physis, Rio de Janeiro, 2007, v. 17, n. 1, p. 43-62.

2. BECK U. O que é globalização? São Paulo: Paz e Terra, 1999

1. BEZERRA IA, COSTA MF. Meio Ambiente: Uma proposta para a educação. Vitória, Seama, 1992.

2. BRASIL. Ministério do Meio Ambiente e Ministério da Educação. Programa Nacional de Educação Ambiental. MMA/MEC, 1999.

3. CAPELETTO JA. Biologia e Educação Ambiental: roteiros de trabalho. $2^{\circ}$ ed. São Paulo: Ática, 1999

4. CARVALHO ICM. Educação ambiental: a formação do sujeito ecológico. 2.ed. São Paulo: Cortez, 2006.

5. CASCINO F. Educação Ambiental: princípios, história, formação de professores. $2^{\circ}$ ed. São Paulo: Editora SENAC, 2000.

6. CRIBB SL. Contribuições da Educação Ambiental e Horta Escolar na promoção de melhorias ao ensino, à saúde e ao ambiente. REMPEC - Ensino, Saúde e Ambiente, 2010, v.3 n 1 p. $42-60$.

7. CURRIE KL. et. al. Meio Ambiente: Interdisciplinaridade na prática. 12ª ed. Campinas, SP: Papirus, 2012

8. DEWEY J. Vida e Educação. Tradução de Anísio Teixeira. 6a ed. São Paulo: Melhoramentos, 1967

9. FERNANDES MC. A Horta Escolar como Eixo Gerador de Dinâmicas Comunitárias, Educação Ambiental e Alimentação Saudável e Sustentável. 2005.

10. FETTER SI, MÜLLER J, SILVA MC. Horta Escolar: Teoria e Prática para uma vida saudável: Educação ambiental na Escola Estadual João Mosmann / Parobé /RS. Revista Brasileira de Agroecologia, Nov. 2006, vol.1

11. FREIRE P. Pedagogia dos sonhos possíveis. São Paulo: UNESP, 2001

12. GADOTTI M. Apresentação e edição brasileira, In: GUTIERREZ, Francisco; PRADO, Cruz. Ecopedagogia e cidadania planetária. São Paulo: Cortez, 2002, p. 23.

13. JACOBI P. Educação ambiental, cidadania e sustentabilidade. Cad. Pesqui. [online]. 2003

14. LOUREIRO FB. Educação ambiental: repensando o espaço da cidadania / 5 ed. São Paulo: Cortez 2011.

15. MORGADO FS, SANTOS MAA. A Horta Escolar na Educação Ambiental e Alimentar: Experiência do Projeto Horta Viva nas Escolas Municipais de Florianópolis. EXTENSIO: Revista Eletrônica de Extensão, Santa Catariana, 2008, n. 6.

16. MORGADO FS. A horta escolar na educação ambiental e alimentar: experiência do Projeto Horta Viva nas escolas municipais de Florianópolis. 2006.

17. NOËL-EVEN J. O liceu experimental de Saint-Nazaire: uma utopia? In: OLIVEIRA, I. B. (Org.). Alternativas emancipatórias em currículo. São Paulo: Cortez Editora, 2004. Série Cultura, Memória e Currículo; vol. 4

18. PIMENTA JC, RODRIGUES KSM. Projeto horta escola: ações de Educação Ambiental na escola Centro Promocional Todos os Santos de Goiânia (GO). In: II SEAT - Simpósio de Educação Ambiental eTransdisciplinaridade. Goiânia, GO, 2011.

19. RODRIGUES IOF, FREIXO AA. Representações e Práticas de Educação Ambiental em Uma Escola Pública do Município de Feira de Santana (BA): subsídios para a ambientalização do currículo escolar. Rev. Bras. de Ed. Ambiental, 2009, v. 4.

20. SORRENTINO M. et al. Educação ambiental como política pública. Educação e Pesquisa, São Paulo, 2005, v. 31, n. 2.

21. SUAVÉ L. Educação e Pesquisa, São Paulo, 2005, v. 31, n. 2, p. 317-322. 